\title{
Offset tracking procedure applied to high resolution SAR data on Viedma Glacier, Patagonian Andes, Argentina
}

\author{
N. Riveros ${ }^{1}$, L. Euillades ${ }^{1}$, P. Euillades ${ }^{1}$, S. Moreiras $^{2}$, and S. Balbarani ${ }^{1}$ \\ ${ }^{1}$ Instituto CEDIAC, Facultad de Ingeniería, Universidad Nacional de Cuyo, Mendoza, Argentina \\ ${ }^{2}$ IANIGLA, Centro Científico y Tecnológico, CONICET - MENDOZA, Mendoza, Argentina
}

Correspondence to: N. Riveros (nriveros@mendoza-conicet.gov.ar)

Received: 5 February 2013 - Revised: 23 May 2013 - Accepted: 24 May 2013 - Published: 25 June 2013

\begin{abstract}
Main aim of this work is to explore the suitability of high resolution SAR images for measuring ice flow velocity within glaciers. Available techniques for this purpose are Differential SAR Interferometry (DInSAR) and Offset Tracking. The former, although theoretically much more precise, is frequently limited by coherence loss (or lacking of coherence) in glacier environment. The latter constitutes an alternative that works well when displacements are large. Study area is the Viedma Glacier (Santa Cruz, Argentina), one of the largest uncovered ice bodies in the South Patagonian Ice (SPI). High resolution COSMO-SkyMed (CSK) acquisitions were processed by estimating range and azimuth offset fields. Useful results, consisting in displacement maps showing areas with different fast-flowing units, were obtained by Offset Tracking processing.
\end{abstract}

\section{Introduction}

Glacier are sensible to climatic conditions and good indicators of climate variations, therefore global climate change effect is evident in the continuous dynamics of glaciers (Bennett and Glasser, 2009; Cuffey and Paterson, 2010). Climate change is associated to temperature and precipitation variations on the Earth and thus impacts on the snow accumulation and melting on the surface of glaciers (Strozzi et al., 2008). Establishing velocities of ice flow let us to understand glacier dynamic in a certain environment (Ritter et al., 2006); besides variability on this parameter may indicate a rapid glacier ablation or an extraordinary glacier advance known as surge (Raymond, 1987) .

Synthetic Aperture Radar (SAR) images have been successfully used for the study of ice and glaciers particularly applying DInSAR (Gray et al., 1998; Rignot et al., 1996; Strozzi et al., 2002a) which allows generating displacement maps with sub-centimeter theoretical accuracy. The application of this technique is limited by the phase noise mainly due, among other sources, to the temporal decorrelation. A usual parameter to characterize the noise is the spatial coherence. On the glacier surface, coherence is usually affected by weather and flow characteristics, so it is clearly related to the time difference between the acquisitions used to calculate the interferograms. A possible cause of temporal decorrelation is the proper glacier motion which is related to sudden and rapid shifts between neighboring pixels. In this context, the use of Offset Tracking with SAR images is an alternative to DInSAR for inferring ice-surface velocity (Ciappa et al., 2010; Derauw, 1999; Strozzi et al., 2002b). It is carried out by using the SAR signal amplitude only, avoiding the necessity of phase unwrapping, being it one of the most critical steps when InSAR/DInSAR techniques are applied. Precision of the results is in this case directly related to the coregistration errors which, depending on the used algorithm, are between $1 / 20$ to $1 / 30$ of pixel size (Casu et al., 2011; Strozzi et al., 2002b). By using scenes acquired by sensors like ERS or ENVISAT, expected errors are in the order of $1 \mathrm{~m}$ (Strozzi et al., 2002b). Considering the resolution of CSK scenes, estimated errors are less than $10 \mathrm{~cm}$, rendering the appropriate precision for typical ice flow velocity characterization. An additional advantage of this methodology is that it can estimate displacements in the direction of radar flight (azimuth); one of the main restrictions of DInSAR.

The aim of this study is to demonstrate the advantages of this technique by applying it to a high resolution CSK dataset of the Viedma Glacier. 


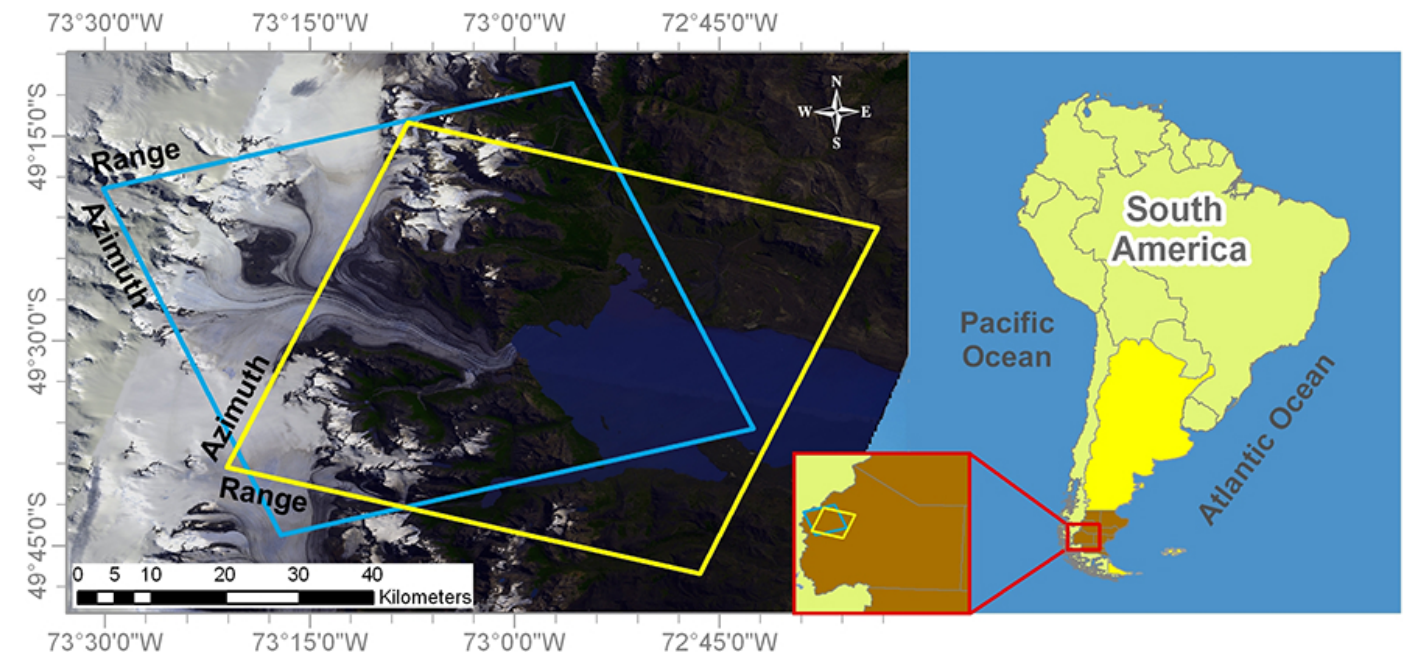

Fig. 1. Viedma Glacier (Santa Cruz province, Argentina). Aster images acquired on February 2005 and 2010 show the area of interest. Area illuminated by COSMO-SkyMed acquisitions is highlighted by square boxes. Yellow box indicates the area covered by the descending orbit whereas blue box indicates that covered by the ascending one. Aster images source is http://terralook.cr.usgs.gov/.

\section{Study area}

Viedma Glacier is placed in Santa Cruz Province, Argentine $\left(49^{\circ} 31^{\prime} \mathrm{S}, 72^{\circ} 59^{\prime} \mathrm{W}\right)$. It is one of the main outlet glacier of the Southern Patagonia Ice Field and the second largest glacier in South America, covering an area of $945 \mathrm{~km}^{2}$ (Aniya et al., 1996). Figure 1 shows the area of interest. In general, the Southern Patagonia Ice Field glaciers are temperated glaciers characterized by a high rate of accumulation and ablation. In-situ data, like precipitation, annual net accumulation or ice flow velocity are generally not available, mainly due to the difficult access to the zone. Thus, the characterization of glacier dynamics usually needs to be carried out by using indirect techniques.

In particular, we focused on the Viedma glacier because the knowledge of its behaviour is rather incomplete. Previous studies have been focused on the estimation of glacier extents and its terminus changes (Aniya et al., 1996; Lopez et al., 2010; Skvarca et al., 1995), but none of them have determined ice velocity maps.

\section{Data processing}

The used datasets is composed by 14 SAR images acquired by the Italian COSMO-SkyMed SAR (X band). Scenes were acquired from April to June 2012 with a revisit time of 1 and 16 days (Table 1). These images have been acquired in ascending and descending orbits, STRIPMAP mode with a look angle of $31.99^{\circ}$ and $\mathrm{HH}$ polarization. Images are combined in pairs for processing. In this study, only tandem pairs (one day difference time between acquisitions) have been processed.
Table 1. COSMO-SkyMed available dataset.

\begin{tabular}{ll}
\hline Date & Orbit \\
\hline $2012-04-28$ & Ascending \\
$2012-04-29$ & Ascending \\
$2012-05-14$ & Ascending \\
$2012-05-15$ & Ascending \\
$2012-06-15$ & Ascending \\
$2012-06-16$ & Ascending \\
$2012-04-30$ & Descending \\
$2012-05-01$ & Descending \\
$2012-05-16$ & Descending \\
$2012-05-17$ & Descending \\
$2012-06-01$ & Descending \\
$2012-06-02$ & Descending \\
$2012-06-17$ & Descending \\
$2012-06-18$ & Descending \\
\hline
\end{tabular}

For estimating ice displacements maps, we employed the Offset-Tracking technique. It relies on the use of a set of SLC (Single Look Complex) SAR images organized in data pairs and properly co-registered to have common reference geometry. The co-registration step must be carried out very accurately since it represents the main source of errors in determining displacement velocities from pixel offset estimation (Casu et al., 2011; Wuite, 2006). Imprecisions in the estimation of pixels offsets could completely mask out the real displacements and the co-registration error vectors may even exceed the displacement components for some data pairs (Rosen et al., 2004). We tried different co-registration algorithms but best results were obtained using a geometric coregistration algorithm (Sansosti et al., 2006), which exploits 

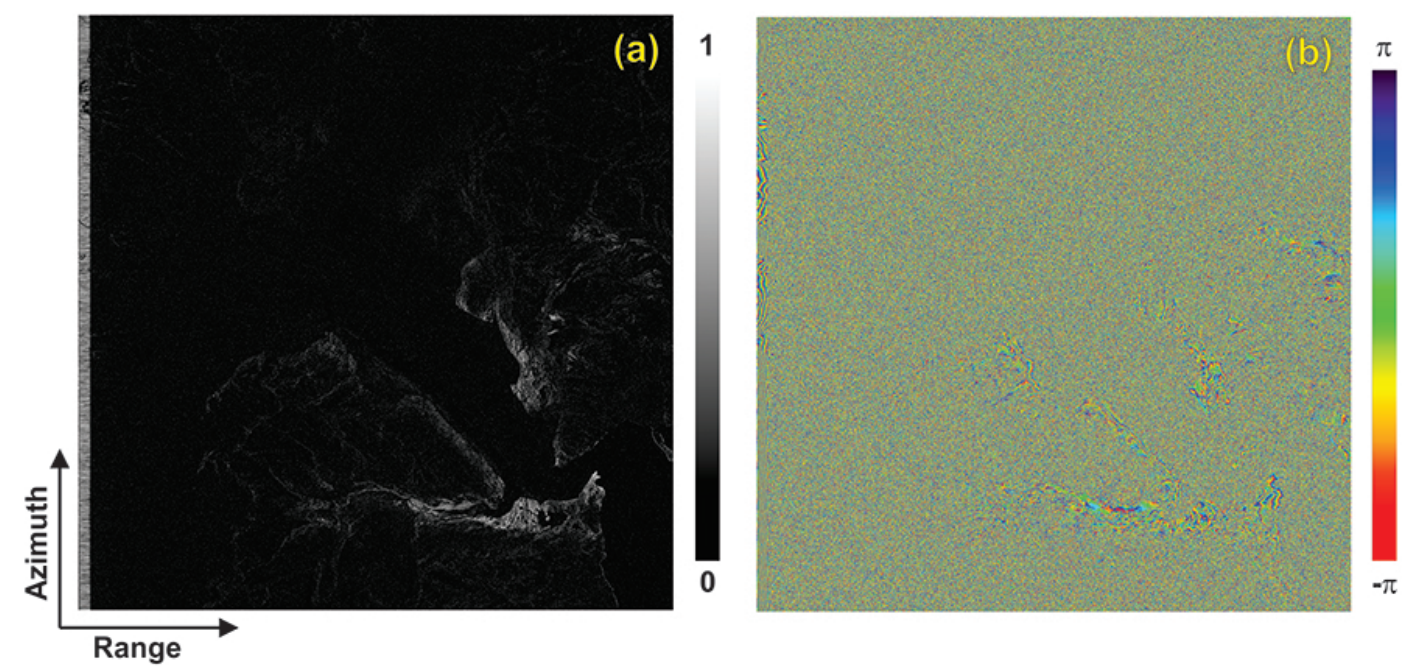

Fig. 2. Interferogram computed between scenes acquired on 31 May 2012 and 16 June 2012 (16 days timespan). (a) interferometric coherence. (b) wrapped interferogram. Loss of coherence is complete over the glacier.

precise orbit information and an external DEM of the investigated area to directly compute the co-registration offsets.

Next, a further fine registration for estimating the relative offsets between pixels is computed. Then residual offsets are converted to local displacements. This estimation is computed by using the co-registration algorithm provided by the Repeat Orbit Interferometry Package (ROI PAC) (Rosen et al., 2004). The procedure is to choose a reference window in the master image according to a specified grid, and compare it with a moving window in the co-registered slave image. The correlation index is calculated for each position of the window slave image. Local displacement is computed as the difference between the master window position and the corresponding correlation peak in the slave image. Main issues in calculating the correlation surface are: (a) the absence of common features in the searching window; (b) search and/or reference window too small with respect to features and (c) too important feature changes between acquisitions (Wuite, 2006).

Pixel offset maps in range and azimuth directions are obtained, which can be easily converted in surface displacements. From them, vector maps can be generated which are a useful way to show the magnitude and direction of the displacements.

The technique has been used to extract the ice velocity vectors for each pair of SAR images. It was tested with different window dimensions (i.e. $50 \times 50,100 \times 100$ and $200 \times 200$ pixels). These values must be chosen according to the expected movement in the glacier. Best results were obtained with window of $100 \times 100$ pixels in both range and azimuth directions. Results have been calculated every 50 pixels in range and azimuth for reducing computational cost. Taking into account the pixel dimension $(\sim 2.4 \mathrm{~m}$ in ground range and $\sim 2.2 \mathrm{~m}$ in azimuth) those values correspond to a square window of $240 \times 220 \mathrm{~m}$, which is in agreement with the displacement occurring on studied SPI glaciers (i.e. Perito Moreno (Ciappa et al., 2010)).

It is important to remark than only a portion of the whole dataset could be successfully used when DInSAR techniques are applied. In general, it is possible to extract range displacement maps from tandem pairs with DInSAR. However, the availability of a huge dataset makes possible combining tandem and not tandem pairs to extract displacement maps (i.e., 1 and 16 days timespan pairs). In particular, reliable results could not have been obtained from 16 days pairs by means of DInSAR mainly due to phase noise in the glacier surface. As an example we show in Fig. 2 the differential interferogram computed between 31 May 2012 and 16 June 2012 (baseline perpendicular is $\sim 94 \mathrm{~m}$; baseline temporal is 16 days). Fringes in the glacier snout are completely obscured by temporal decorrelation phenomena.

\section{Results}

Despite Viedma is not an extensively studied glacier, we expect a similar dynamic behaviour when compared with neighbouring ones, and so it can be considered relevant as a study area. The examples analysed here include two pairs of scenes acquired during 15-16 June 2012 (ascending pass) and 17-18 June 2012 (descending pass). Figure 3 shows ice flow velocity component maps in range (ground projected) and azimuth directions computed from the ascending pair. Due to changes in the relative orientation between ice flow and SAR orbit, range and azimuth components of the velocity take positive or negative values in different regions within the glacier, as evidenced in Fig. 3. Velocity range and azimuth components clearly show alternating maximums and minimums, highlighted with arrows in Fig. 3. High range 

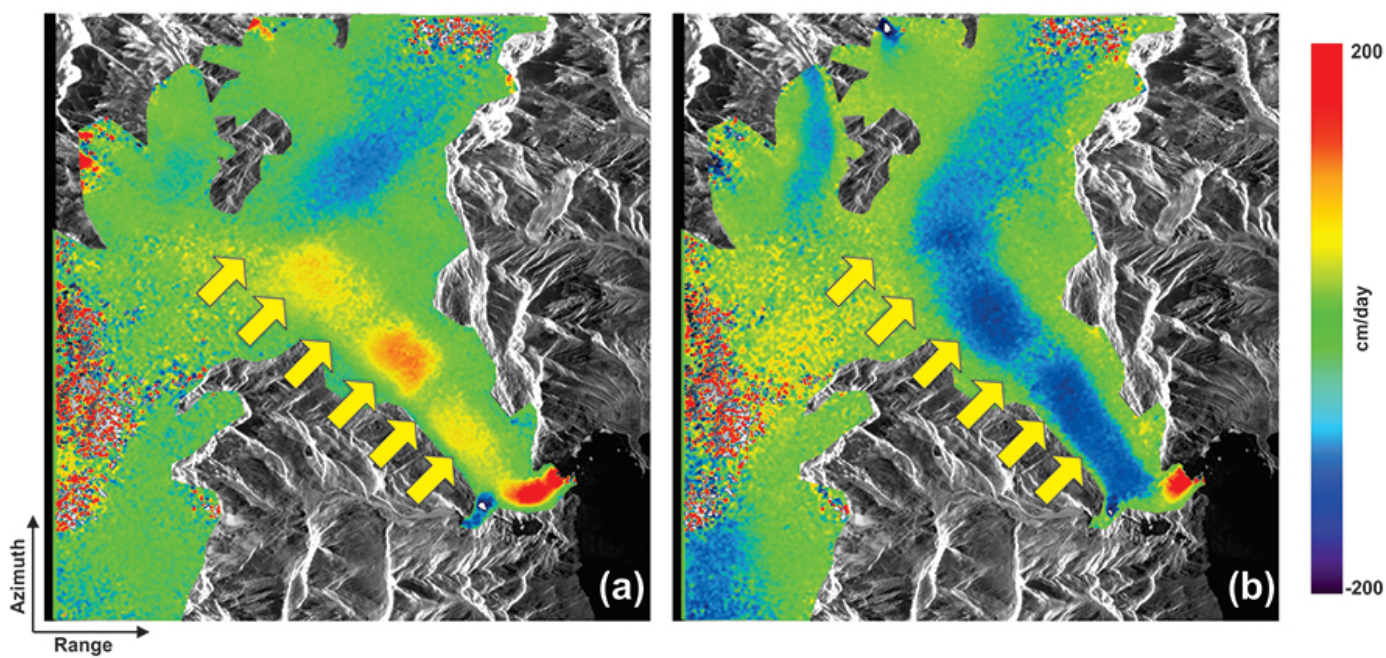

Fig. 3. Offset field in range direction (a) and azimuth direction (b) computed from ascending COSMO-SkyMed SAR images of 15 June 2012 and 16 June 2012.

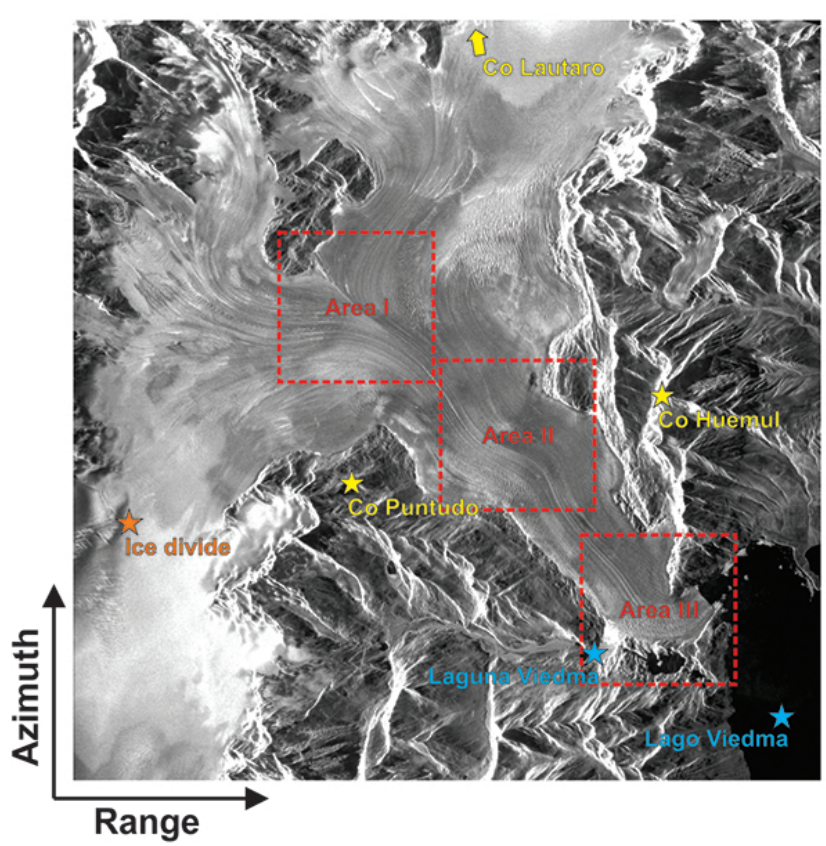

Fig. 4. Amplitude image corresponding to the scene acquired on 15 June 2012 ascending pass. Some reference points have been identified by using coloured stars. Dashed square boxes indicate the areas over the Viedma glacier that have been analysed.

velocity areas are coincident with low azimuth velocity areas and vice versa. The reason for this behaviour becomes clear by observing the amplitude image in Fig. 4, in which the ice flow sinuous nature is evidenced by the ash band and the medial moraines (light and dark flow lines within the ice).

For better understanding the flow nature it is useful to compute the actual velocity modulus and direction instead of analysing the components separately. Figures 5 and 6 show the vector representation of ice flow velocity in both ascending and descending passes.

We focused the attention in three different areas denoted in Fig. 4 by using square boxes:

a. Area I. Tributaries of Viedma glacier have different origins. Main streams originate near Cerro Lautaro (NorthWest) and at the ice divide of the Upsala glacier's tributaries (South-West), see Fig. 4. Area I corresponds to the zone where both main tributaries of Viedma glacier get together. Figures $5 \mathrm{~b}$ and $6 \mathrm{~b}$ show the assessment for ice velocity from ascending and descending pass respectively, which are in the order of $\sim 0.4$ to $\sim 1.1 \mathrm{~m} \mathrm{day}^{-1}$. Note how the direction of the computed velocity vectors follows the flow lines of both tributaries converging into a common flow line in the central part of the glacier.

b. Area II. Central part of the glacier. Velocity vectors are in very good agreement with the flow lines evidenced by glacier features like medial moraines. Area of maximum velocity is located at the intersection of the glacier with an imaginary straight line between Cerro Huemul and Cerro Puntudo, see Fig. 4. Location is consistent in ascending and descending pass results, as can be seen in Figs. 5c and 6c, respectively. However, velocity computed from ascending and descending pass scenes reach $\sim 1.4 \mathrm{~m} \mathrm{day}^{-1}$ and $\sim 2 \mathrm{~m} \mathrm{day}^{-1}$ respectively. The keys for explaining this observations could be: (1) acquisitions are made in different days, (2) acquisitions are made in different hours: ascending pass at 08:45 (HH:MM local time), descending pass at 18:45 (HH:MM local time), (3) a simplification in the slant range to ground range velocity component conversion, consistent in not using the true incidence angle which varies between ascending and descending passes. 

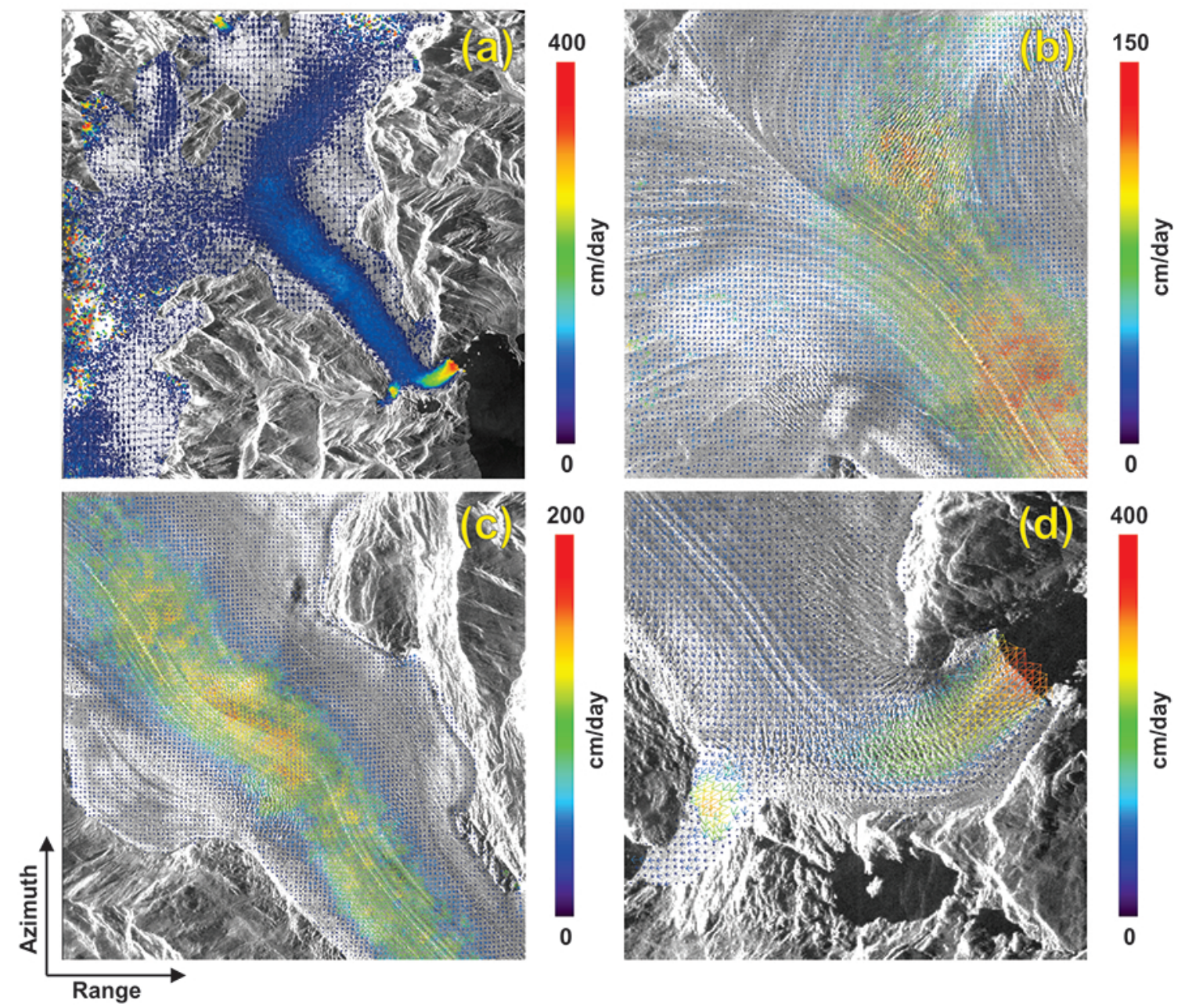

Fig. 5. Ice velocity field computed by Offset Tracking from COSMO-SkyMed ascending tandem pairs (15-16 June 2012). (a) shows the area indicated by the blue box in Fig. 1 and (b-d) are parts of the ice velocity map corresponding to the areas indicated in Fig. 4. (Note that the color bars are different.)

c. Area III. Glacier terminus. Figures $5 \mathrm{~d}$ and $6 \mathrm{~d}$ show the results for ascending and descending pass respectively, where very high velocities are observed in the terminus, both in Lago Viedma and Laguna Viedma, reaching $\sim 3 \mathrm{~m} \mathrm{day}^{-1}$. According to Skvarca et al. (1995); White and Copland (2013) Viedma glacier retreated significantly between 1981 to late 2000 . To the best of our knowledge, no more recent studies were published about the glacier's extension, retreating or flow velocity. Our observation of high velocity in the terminus could be an evidence of rapid retreating still on-going nowadays.

\section{Conclusions}

We demonstrated how using a high resolution SAR sensor allows characterizing Viedma glacier velocity field with a relatively high accuracy level. We remark that this study is the first in its type carried out over this glacier. Future work will be oriented to understanding if the partial disagreement between ascending and descending pass results is associated to processing issues or glacier behaviour, as suggested in the previous section. Processing more data pairs will allow us to characterize temporal velocity evolution and 3-D displacement vectors.

Both high geometric resolution and short revisit time render the constellation of X-band SAR COSMO-SkyMed satellites a useful source of information for investigating the glacier dynamics. In particular, the study of small glaciers like those located in the Central Andes could benefit from its resolution and accuracy. We remark that this field was not very exploited in the past due to the relatively low resolution of the previously available SAR sensors. Furthermore, the application of Offset tracking technique is relatively straightforward, fast and economical if compared to traditional methods of glacier monitoring like GPS or stakes. 

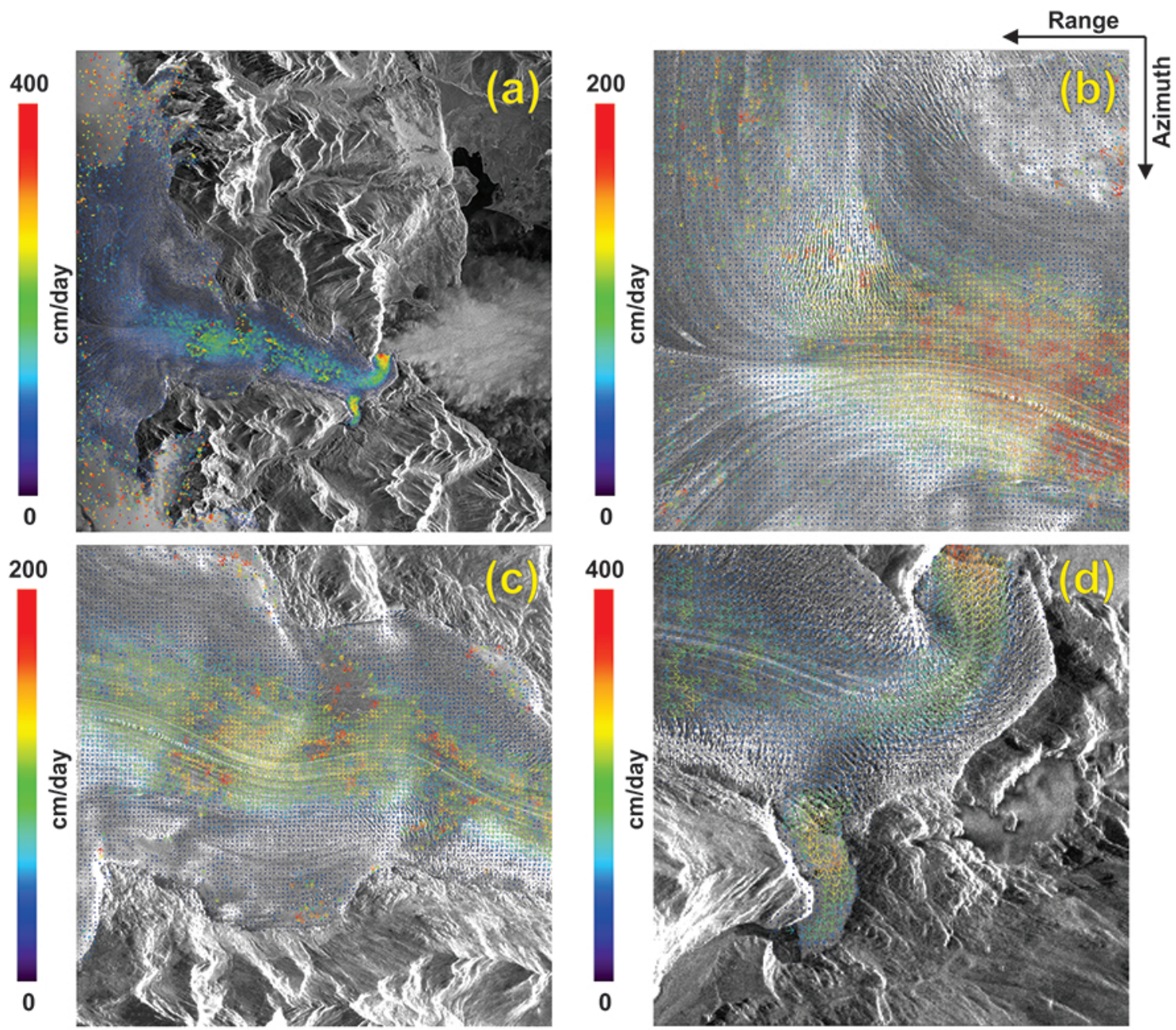

Fig. 6. Ice velocity field computed by Offset Tracking from COSMO-SkyMed descending tandem pairs (17-18 June 2012). (a) shows the area indicated by the yellow box in Fig. 1 and (b-d) are parts of the ice velocity map corresponding to the areas indicated in Fig. 4. (Note that the color bars are different.)

Although this technique is known worldwide, it has not been widely applied in South American glaciers. This fact is relevant for climate studies of the Patagonian Andes where access to the main glaciers is very difficult.

Acknowledgements. Authors are grateful to CONAE for its support and to Dominique Derauw and Francesco Casu for their very insightful comments and corrections to the original manuscript.

Edited by: K. Tokeshi

Reviewed by: F. Casu and one anonymous referee

\section{References}

Aniya, M., Sato, H., Naruse, R., Skvarca, P., and Casassa, G.: The use of satellite and airborne imagery to inventory outlet glaciers of the Southern Patagonia Icefield, South America, Photogramm. Eng. Rem. S., 62(12), 1361-1369, 1996.

Bennett, M. and Glasser, N. F.: Glacial geology: ice sheets and landforms, Wiley-Blackwell, Chichester, UK, Hoboken, NJ, 2009.

Casu, F., Manconi, A., Pepe, A., and Lanari, R.: Deformation Time-Series Generation in Areas Characterized by Large Displacement Dynamics: The SAR Amplitude Pixel-Offset SBAS Technique, IEEE T. Geosci. Remote, 49(7), 2752-2763, doi:10.1109/TGRS.2010.2104325, 2011.

Ciappa, A., Pietranera, L., and Battazza, F.: Perito Moreno Glacier (Argentina) flow estimation by COSMO SkyMed sequence of high-resolution SAR-X imagery, Remote Sens. Environ., 114(9), 2088-2096, doi:10.1016/j.rse.2010.04.014, 2010.

Cuffey, K. M. and Paterson, W. S. B.: The physics of glaciers, Elsevier, Amsterdam, 2010. 
Derauw, D.: DInSAR and coherence tracking applied to glaciology: The example of Shirase Glacier, in FRINGE99 workshop, available online: http://earth.esa.int/pub/ESA_DOC/fringe1999/ Papers/derauw.pdf (last access: 17 June 2013), 1999.

Gray, A. L., Mattar, K. E., Vachon, P. W., Bindschadler, R., Jezek, K. C., Forster, R., and Crawford, J. P.: InSAR results from the RADARSAT Antarctic Mapping Mission data: estimation of glacier motion using a simple registration procedure, in Geoscience and Remote Sensing Symposium Proceedings, 1998, IGARSS'98, 1998 IEEE International, Vol. 3, 1638-1640, 1998.

Lopez, P., Chevallier, P., Favier, V., Pouyaud, B., Ordenes, F., and Oerlemans, J.: A regional view of fluctuations in glacier length in southern South America, Global Planet. Change, 71(1-2), 85108, doi:10.1016/j.gloplacha.2009.12.009, 2010.

Raymond, C. F.: How do glaciers surge? A review, J. Geophys. Res., 92(B9), 9121, doi:10.1029/JB092iB09p09121, 1987.

Rignot, E., Forster, R., and Isacks, B.: Interferometric radar observations of Glacier San Rafael, Chile, J. Glaciol., 42(141), 279291, 1996.

Ritter, D. F., Kochel, R. C., and Miller, J. R.: Process geomorphology, Waveland Press, Long Grove, Ill., 2006.

Rosen, P. A., Hensley, S., Peltzer, G., and Simons, M.: Updated repeat orbit interferometry package released, Eos, Transactions American Geophysical Union, 85(5), 47, doi:10.1029/2004EO050004, 2004.

Sansosti, E., Berardino, P., Manunta, M., Serafino, F., and Fornaro, G.: Geometrical SAR image registration, IEEE T. Geosci. Remote, 44(10), 2861-2870, doi:10.1109/TGRS.2006.875787, 2006.
Skvarca, P., Rott, H., and Stuefer, M.: Synergy of ERS-1 SAR, XSAR, Landsat TM imagery and aerial photography for glaciological studies of Viedma Glacier, southern Patagonia, in: Proceedings, VII Simposio Latinoamericano de Percepción Remota, 674-682, SELPER, Puerto Vallarta, México, 1995.

Strozzi, T., Gudmundsson, G. H., and Wegmüller, U.: Estimation of the surface displacement of Swiss alpine glaciers using satellite radar interferometry, in: Proceedings, EARSeL-SIG-Land Ice and Snow workshop, Berne, Switzerland, available online: http://las.physik.uni-oldenburg.de/eProceedings/vol02_1/ 02_1_strozzi1.pdf (last access: 17 June 2013), 2002a.

Strozzi, T., Luckman, A., Murray, T., Wegmuller, U., and Werner, C. L.: Glacier motion estimation using SAR offset-tracking procedures, IEEE T. Geosci. Remote, 40(11), 2384-2391, doi:10.1109/TGRS.2002.805079, 2002b.

Strozzi, T., Kouraev, A., Wiesmann, A., Wegmüller, U., Sharov, A., and Werner, C.: Estimation of Arctic glacier motion with satellite L-band SAR data, Remote Sens. Environ., 112(3), 636-645, doi:10.1016/j.rse.2007.06.007, 2008.

White, A. and Copland, L.: Spatial and temporal variations of glacier extent across the Southern Patagonian Icefield since the 1970s, The Cryosphere Discuss., 7, 1-34, doi:10.5194/tcd-7-12013, 2013.

Wuite, J.: Spatial and temporal dynamics of three East Antarctic outlet glaciers and their floating ice tongues, available online: http://adsabs.harvard.edu/abs/2006PhDT.......132W (last access: 17 June 2013), 2006. 